\title{
Open and Closed Positions and Stock Index Futures Volatility
}

\author{
Óscar Carchano, Julio Lucia and Ángel Pardo
}

Óscar Carchano (corresponding author),

Department of Financial Economics, Avda de los Naranjos s/n, Faculty of Economics, University of Valencia, 46022 Valencia, Spain.

e-mail: oscar.carchano@uv.es

Julio Lucia,

Department of Financial Economics, Avda de los Naranjos s/n, Faculty of Economics, University of Valencia, 46022 Valencia, Spain.

e-mail: julio.j.lucia@uv.es

Ángel Pardo,

Department of Financial Economics, Avda de los Naranjos s/n, Faculty of Economics, University of Valencia, 46022 Valencia, Spain.

e-mail: angel.pardo@uv.es

Phone number: +0034963828377

Fax number: +0034963828370

\begin{abstract}
In this paper we analyze the relationship between volatility in index futures markets and the number of open and closed positions. We observe that, although in general both positions are positively correlated with contemporaneous volatility, in the case of S\&P 500, only the number of open positions has influence over the volatility. Additionally, we observe a stronger positive relationship on days characterized by extreme movements of these contracting movements dominating the market. Finally, our findings suggest that daytraders are not associated to an increment of volatility, whereas uninformed traders, both opening and closing their positions, have to do with it.
\end{abstract}

Keywords: volatility; open interest; trading volume. 


\section{INTRODUCTION}

We show that it is possible to obtain the daily total number of positions that are entered into as well as the daily total number of positions that are closed out in any futures contract, based on the daily volume of trading and open interest figures. As far as we know, this possibility is acknowledged for the first time in this paper. It allows exploring the relationships between any of the two components of the trading volume and any variable of interest, separately.

A line of research has studied the link among a given measure of price variability and some trading-related variables in futures markets. On this regard, the available literature has focused on the influence of the volume of trading and some variable related to the open interest on volatility. This previous research lacks of a homogeneous framework and has provided inconclusive results.

The objective of this paper is to study the relation between volatility and some tradingrelated variables under a new unifying setting, by concentrating on contracting activity (i.e., the flow of contracts entered into and closed out) instead of trading activity. To this aim, we analyse empirically the linkage between daily volatility and the number of open and closed positions for three of the most important stock index futures markets in the world.

For the DAX and Nikkei futures, we find that both contemporaneous open and closed positions have a positive relationship with volatility, while they have the opposite effect on the following day. However, for the S\&P 500 futures, only the contemporaneous number of opening positions has a positive relationship with volatility, although again the lagged numbers of opening and closing positions have a negative relationship. Nonetheless, for this index futures contract, the contemporaneous number of closing positions is positively related to volatility on those days dominated by agents that are closing previously opened positions. In addition, the positive correlations between the daily volatility and the numbers

of open and closed positions are usually more prominent when either the opening or the closing of positions predominates, respectively. 
The remainder of the paper is organized as follows. Section 2 reviews the previous literature on the relationship between volatility, and volume and open interest. Section 3 the variables used in the empirical analysis are motivated, and it is explained how they have been computed. A daily futures volatility of the Garman-Klass type is calculated and its descriptive statistics are presented. Section 4 presents the empirical methods and results. The conclusions of the paper are summarized in Section 5.

\section{REVIEW OF LITERATURE}

The relation between diverse measures of price variability and trading volume for index futures has been investigated extensively. Several studies show a positive and contemporaneous relationship between volume and volatility. There is evidence that documented a positive relation between volume and volatility for different stock index futures at different frequencies of data. (See, for example, Kawaller et al. (1994), and Gannon (1995) for intraday data, and Raghunathan and Peker (1997), ap Gwilym et al. (1999), Wang and Yau (2000), Watanabe (2001), and Pati (2008) for daily data, and finally Wang (2002) for weekly data.) ${ }^{1}$

There are also studies that indicate that lagged volume is related to volatility as well. Nonetheless, in this case, ap Gwilym et al. (1999), and Wang and Yau (2000) found that a negative relationship between lagged trading volume and price variability, by analyzing stock index futures among other financial assets. ${ }^{2}$

Another variable that is thought to have a relation with volatility is the level of the open interest in the futures market. This variable is of special relevance for two reasons. Firstly, it is a trading-related measure that only appears in derivative markets. Secondly, there is a controversy about its influence on volatility. Whereas Watanabe (2001), Li (2007), and

\footnotetext{
${ }^{1}$ Furthermore, there is evidence that supports the same relation in the case of equities (see Epps and Epps (1976), Smirlock and Starks (1985) and Schwert (1989)), as well as commodities (see Garcia et al. (1986)).

${ }^{2}$ It seems that this relationship is general for most financial assets. Foster (1995) studied crude oil futures markets, and they determined that lagged volume can partially explain current price variability. Fung and Patterson (1999) studied five currency futures markets and found the same negative relation between return volatility and past trading volume.
} 
Pati (2008) observe a negative link between open interest and volatility in several stock index futures markets, Chen, Cuny, and Haugen (1995) proved a positive link for S\&P 500 futures. ${ }^{3}$ Thus, depending on the stock index futures contract, it has been showed one relationship or another.

The literature that explores the relationship between volatility, on one side, and trading volume and open interest, on the other, however, lacks of unifying explanations and interpretations. First of all, there are several competing theories on the ultimate variable of study that is getting proxied by any given observed trading-related variable. Indeed, whereas for some researchers volume and open interest are simply two broad liquidityrelated variables, for others they are related to the trading activity carried out by some specific type of traders. Thus, while volume is sometimes taken to be the simplest and more direct liquidity variable and open interest is taken to be a proxy for market depth in futures markets, other times, on the contrary, volume and open interest are assumed to be proxies, respectively, for the trading activity by informed traders, or speculators, and uninformed traders, or hedgers (see Bessembinder and Seguin (1993)).

In this vein, the multiplicity of interpretations for the trading-related variables also explains the multiple ways in which the basic trading-related variables (namely, volume and open interest) have been related to price variability. Indeed, as has been surveyed before, not only the relationship between volatility and contemporaneous volume and open interest has been studied extensively, but also the price variability has been related to lagged volume. Not surprisingly, there are also competing motivations for the inclusion of lagged volume in analysing the relationship of trading-related variables with volatility (Wang and Yau (2000), for instance, believed that a lagged trading volume increment implied a reduction in the contemporaneous volatility, taking volume as a measure of liquidity.) ${ }^{4}$ Also several

\footnotetext{
${ }^{3}$ A negative relationship is also detected in agricultural, currency, oil and metal futures contracts (see among others, Bessembinder and Seguin (1993), Fung and Patterson (1999), and Ripple and Moosa (2009)). A second group of papers finds a null or weak connection between volatility and open interest. This is the case of Martinez and Tse (2007) stock index as well as currency futures contracts. See also Yang et al. (2005), for agricultural futures markets. Figlewski (1981) proved a positive link for Government National Mortgage Association (GNMA) futures.

${ }^{4}$ Foster (1995) studied crude oil futures markets, and they determined that lagged volume can partially explain current price variability. It could be due to traders conditioning their prices on previous trading volume as a measure of market sentiment. Or it could be explained also by a form of mimetic contagion 
variables based on the change in open interest have been related to the variability of prices. These variables are intended to provide a good proxy for a given ultimate factor that may be related to volatility (for example, García et al. (1986), whom created a volume-to-openinterest ratio in order to measure the relative importance of the speculative behaviour in a given contract ${ }^{5}$ ).

We tried to shed light on this conundrum, by investigating the relationship between price variability and trading-related variables in futures markets, under a new perspective. Indeed, the focus on the contracting activity allows a new clear and direct explanation. Nevertheless, we also relate our results to the previous literature, which concentrates on the trading activity instead. This is due to the fact that the trading variables traditionally related to volatility can be expressed in terms of the number of open and closed positions, both contemporaneous and lagged, as we prove in the next section.

\section{VARIABLES COMPUTATION AND DATA}

In this paper we relate some trading-related variables to a measure of price variability in futures markets. We begin with the motivation of the trading-related variables that are used in the empirical analysis in the paper, and an explanation of the way they have been computed.

\subsection{TRADING-RELATED VARIABLES}

Traditionally, volume and open interest have been used as the basic trading-related variables in derivatives markets. The daily trading volume (denoted $V_{t}$ ) simply accounts for the amount of trading activity that has taken place in a specific contract on a trading date $t$,

where agents set their prices with reference to the trading patterns of other agents. Fung and Patterson (1999) studied five currency futures markets and found the same negative relation between return volatility and past trading volume, and they thought that it was consistent with the overreaction hypothesis what suggests a high volume of trading in the stock as well as a sharp price response -Conrad et al. (1994).

${ }^{5}$ See Lucia and Pardo (2010) for a critique of this line of research. 
whereas the daily open interest figure $\left(O I_{t}\right)$ determines the number of outstanding contracts at the end of the trading date $t$.

It occurs that both daily figures are related to the total number of open positions over day $t$ (denoted $O P_{t}$ ) as well as the total number of closed positions over day $t\left(C L_{t}\right)$. This is because, since every trade involves two parties (long and short) and each party either opens or closes out a position, the total number of open and closed positions equals the total number of positions involved in the contracts traded (i.e. twice the number of traded contracts):

$$
O P_{t}+C L_{t}=2 V_{t}
$$

Furthermore, the sum of all the open positions from the first trading day of the contract up to the end of day $t$ minus the sum of all the closed positions up to the same moment must be equal to the total number of outstanding (long plus short) positions at the end of day $t$ (i.e. twice the open interest at the same moment), that is:

$$
\sum_{s=1}^{t}\left(O P_{s}-C L_{s}\right)=2 O I_{t}
$$

If we define the change in open interest as $\Delta O I_{t}=O I_{t}-O I_{t-1}$, from equation (2), it follows that:

$$
O P_{t}-C L_{t}=2 \Delta O I_{t}
$$

Now, from equations (1) and (3), the following accounting relationships can be easily obtained:

$$
\begin{aligned}
& O P_{t}=V_{t}+\Delta O I_{t} \\
& C L_{t}=V_{t}-\Delta O I_{t}
\end{aligned}
$$

It is important to notice that although $O I_{t}$ is a stock variable measured at the end of day $t$, the change in open interest over day $t, \Delta O I_{t}$, is a flow variable, just as the trading volume, which depend only on the behaviour of traders on the observational day. 
Finally, we can also define the relative net number of open positions on day $t$, denoted by $R N O P_{t}$, as opening positions minus closing positions on trading day $t$ in relative terms over the total number of positions involved. Mathematically:

$$
R N O P_{t}=\frac{O P_{t}-C L_{t}}{O P_{t}+C L_{t}}
$$

It is easily checked that $R N O P_{t}$ equals $\Delta O I_{t} / V_{t}$, which shows that $R N O P_{t}$ coincides with the so-called $R 3_{t}$ ratio introduced by Lucia and Pardo (2010) in the context of a critical assessment of the literature devoted to measure hedging activity from volume and open interest data.

We can also get:

$$
\begin{aligned}
& O P_{t}=V_{t}\left(1+R N O P_{t}\right) \\
& C L_{t}=V_{t}\left(1-R N O P_{t}\right)
\end{aligned}
$$

As Lucia and Pardo (2010) pointed out, the RNOP variable (or R3, as they called it) can only take values from -1 to +1 . Now, equations (6), (7), and (8) allow a convenient interpretation of the extreme values that can be taken by RNOP in terms of the number of open and closed positions. If $R N O P$ takes the value +1 on any given day, this means that all the parties involved in every transaction occurred during the day have taken new positions in the contract. On the contrary, if RNOP takes the value -1 , all the parties involved in every trade have liquidated old positions (i.e. they cancel their outstanding commitments). Interestingly, whenever RNOP equals zero, the total number of open positions equals the total number of closed positions. As Lucia and Pardo (2010) also pointed out, this may occur when every trade either is a day-trade or implies that one side involved in the trade replaces the other side in his position.

The purpose of this paper is to explore the role of open and closed positions on daily futures volatility taking into account the mechanical links reviewed in this section. Furthermore, using relative combinations of such positions, we are also able to study the 
effects generated by opening trades and closing trades into the price volatility of market activity when one of these groups of trades predominates in the market.

\subsection{MEASUREMENT OF VOLATILITY}

Recall that we only deal with flow variables in this paper. Hence, to be consistent, we use a measure of daily volatility, which only depends on the behaviour of traders on the observational period that runs from time $t-1$ to time $t$.

Taking into account open, close, high and low prices, we calculate a daily volatility measure of the Garman-Klass-type in the following manner:

$$
V_{G K_{\mathrm{t}}}=\left[\ln \left(\frac{O_{\mathrm{t}}}{c_{\mathrm{t}-1}}\right)\right]^{2}-0.383 \ln \left(\frac{C_{\mathrm{t}}}{O_{\mathrm{t}}}\right)+\frac{1.364}{4 \ln 2}\left[\ln \left(\frac{H_{\mathrm{t}}}{L_{\mathrm{t}}}\right)\right]^{2}+0.019\left[\ln \left(\frac{H_{\mathrm{t}}}{\sigma_{\mathrm{t}}}\right) \ln \left(\frac{H_{\mathrm{t}}}{C_{\mathrm{t}}}\right)+\ln \left(\frac{L_{\mathrm{t}}}{O_{\mathrm{t}}}\right) \ln \left(\frac{L_{\mathrm{t}}}{c_{\mathrm{t}}}\right)\right]
$$

where $O_{t}, C_{t}, H_{t}$ and $L_{t}$ are the open, close, high and low prices on day $t$ and $C_{t-1}$ is the close price on day $t-1$.

Equation (9) is based on Yang and Zhang (2000). Following the assumptions of Parkinson (1980), Rogers and Satchell (1991), Rogers, Satchell and Yoon (1994) and Garman and Klass (1980), these authors make explicit the following formula for the efficient (minimum-variance) drift-independent unbiased estimator of Garman and Klass for the variance of a financial series, based on $n$ observations:

$$
V_{G K}=V_{o}^{\prime}-0.383 V_{c}^{\prime}+1.364 V_{p}+0.019 V_{R S}
$$

where $V_{o}^{\prime}$ and $V_{c}^{\prime}$ are defined as:

$$
\begin{aligned}
& V_{o}^{\prime}=\frac{1}{n} \sum_{i=1}^{n} o_{i}^{2} \\
& V_{c}^{\prime}=\frac{1}{n} \sum_{i=1}^{n} c_{i}^{2}
\end{aligned}
$$


and $V_{P}$ (Parkinson (1980)) and $V_{R S}$ (Rogers and Satchell (1991)) are defined as:

$$
\begin{gathered}
V_{p}=\frac{1}{n} \sum_{i=1}^{n} \frac{1}{4 \ln 2}\left(u_{i}-d_{i}\right)^{2} \\
V_{R S}=\frac{1}{n} \sum_{i=1}^{n}\left[u_{i}\left(u_{i}-c_{i}\right)+d_{i}\left(d_{i}-c_{i}\right)\right]
\end{gathered}
$$

where:

$o_{i}=\ln O_{i}-\ln C_{i-1}$, is the so-called normalized open;

$u_{i}=\ln H_{i}-\ln O_{i}$, is the normalized high;

$d_{i}=\ln L_{i}-\ln O_{i}$, is the normalized low;

and $c_{i}=\ln C_{i}-\ln O_{i}$, is the normalized close.

The specification in equation (9) is obtained from (10) to (14), when the computation of the estimator is based on single-period data ( $n=1$, in the observational period $[t-1, t]$ ).

\subsection{DATA SERIES AND DESCRIPTIVE STATISTICS}

The stock index futures contracts selected for our empirical study are S\&P 500, DAX, and NIKKEI. Our database has been taken from Reuters and consists of the daily open, high, low, and close prices, as well as the daily volume and open interest series for the sixteen year period that runs from December 2, 1991 to April 30, 2008.

For each variable, we construct a unique continuous-time series using the different maturities of each futures index following the methodology proposed by Carchano and Pardo (2009). ${ }^{6}$

\footnotetext{
${ }^{6}$ The last trading day of the front contract has been chosen as the rollover date. Following their idea, in order to avoid the rollover jump, we have calculated the normalized open of the day after the rollover date as the difference between the logarithm of the opening price of that day and the logarithm of the previous closing price of the same contract. By doing so, all the prices are taken from the same maturity.
} 
Finally, we create a daily volatility series for the period from December 2, 1991 to April 30, 2008, from equation (9). Table 1, Panel A, reports the descriptive statistical properties of the three volatility series.

\section{TABLE 1. DESCRIPTIVE STATISTICS AND SAMUELSON HYPOTHESIS TEST}

Panel A presents the maximum, mean, minimum and standard deviation statistics of the future daily return volatility of the S\&P 500, DAX and Nikkei for the for the period from December 2, 1991 to April 30, 2008. Panel B presents the results for testing the Samuelson hypothesis using daily return volatility of the S\&P 500, DAX and Nikkei for the for the same period. The results are based on the regression $V_{G K_{t}}=\alpha+\beta T t M_{t}+\varepsilon_{t}$, where the dependent variable $V_{G K_{t}}$, is the daily Garman and Klass volatility. The independent variable $\mathrm{TtM}_{\mathrm{t}}$ is the time to maturity, measured as the number of days until expiration. The results are obtained with the Newey and West (1987) heteroskedasticity consistent covariance procedure; $\mathrm{p}$-values are given in parenthesis. Finally, adjusted- $\mathrm{R}^{2}$ is presented.

Panel A: Descriptive statistics of the futures daily return volatility

\begin{tabular}{lccc}
\hline & S\&P 500 & DAX & Nikkei \\
\cline { 2 - 4 } Maximum & 0.0473 & 0.0703 & 0.0388 \\
Mean & 0.0068 & 0.0084 & 0.0081 \\
Minimum & 0.0002 & 0.0010 & 0.0000 \\
Standard Deviation & 0.0043 & 0.0056 & 0.0042 \\
\hline
\end{tabular}

Panel B: Testing for the Samuelson hypothesis using daily return volatility

\begin{tabular}{lccc}
\hline & S\&P 500 & DAX & Nikkei \\
\cline { 2 - 4 } Intercept & 0.0065 & 0.0082 & 0.0078 \\
(p-value) & $(0.0000)$ & $(0.0000)$ & $(0.0000)$ \\
TTM & $9.56 \mathrm{E}-06$ & $5.95 \mathrm{E}-06$ & $7.15 \mathrm{E}-06$ \\
(p-value) & $(0.1984)$ & $(0.5841)$ & $(0.3053)$ \\
Adjusted-R $^{2}$ & 0.0014 & 0.0001 & 0.0007 \\
\hline
\end{tabular}


It shows that DAX futures market has the highest daily volatility. ${ }^{7}$ Also, all the other basic descriptive statistics take the highest values for the DAX futures contract volatility.

Before exploring the relationship between volatility and our chosen trading-related variables, we have studied the existence of seasonal volatility due to the maturity of futures contracts. Specifically, we have studied the fulfilment of the Samuelson hypothesis, which postulates that the futures price volatility increases as the futures contract approaches its expiration. If this were the case, a time-to-maturity variable would be needed to control for this effect in our empirical analysis.

In order to test the Samuelson hypothesis, we have estimated the following regression:

$$
V_{G K_{t}}=\alpha+\beta T t M_{t}+\varepsilon_{t}
$$

where the dependent variable $V_{G K_{t}}$, is the daily Garman and Klass volatility and $T t M_{t}$ is the time to maturity measured as the number of days until expiration. For the Samuelson hypothesis to hold, the $\beta$ coefficient of time to maturity should be negative and statistically significant.

Panel B of Table 1 shows the results. Any beta coefficient is not significant for our three stock index futures series. ${ }^{8}$ Therefore, in our empirical study, it will not be necessary to introduce a time-to-maturity variable in order to control for the Samuelson effect.

\footnotetext{
${ }^{7}$ The Anova F-tests of equality of mean volatility reveal that the null is rejected at the $1 \%$ of significance level between DAX and S\&P 500 and between DAX and Nikkei.

${ }^{8}$ Our results are in line with those obtained recently by Duong and Kalev (2008), who analyze 20 futures contracts, including the S\&P 500, and find strong support for the Samuelson hypothesis only for agricultural futures.
} 


\section{EMPIRICAL METHODS AND RESULTS}

\subsection{METHODOLOGY}

In order to investigate the relationship between the intraday volatility and the flows of entering trades and cancelling trades, we run the following regression:

$$
\begin{aligned}
\sigma_{t}^{2}= & \alpha_{0}+\sum_{l=1}^{L} \alpha_{l} \sigma_{t-l}^{2}+\beta_{0} O P_{t}+\beta_{1} O P_{t-1}+\gamma_{0} C L_{t}+\gamma_{1} C L_{t-1} \\
& +\delta_{1} R N O P(50 \%)_{t}+\delta_{2}\left[O P_{t} \times \operatorname{RNOP}(95 \%)_{t}\right]+\delta_{3}\left[C L_{t} \times R N O P(5 \%)_{t}\right]+\varepsilon_{t}
\end{aligned}
$$

The regressors in the model can be classified into three groups. First, we include an arbitrarily long set of autoregressive coefficients to accommodate the persistence of volatility shocks in a simple way, following Schwert (1990). This is motivated by the results of Wang and Yau (2000) and Li (2007), which show the importance of taking into account the persistence in volatility in the analysis of the relationship between volatility and some trading-related variables, for the S\&P 500 and Asian stock index futures contracts, respectively. ${ }^{9}$ The appropriate number of lags $L$ to be included is determined empirically.

Second, we include the number of open and closed positions together with their respective lagged values. We add the lagged number of open and closed positions separately in order to add flexibility to the model. We will exploit this flexibility later on.

Third, we add three variables designed to indicate a distinct relationship when either the sign of RNOP is undefined, or this ratio is close to one of the two possible extreme values. To this aim, we first define three dummy variables related to RNOP. The first one is $R N O P(50 \%)$ and is intended to indicate those days in which almost every trader who has opened a position has closed it before the market close. This variable takes the value 1 the

\footnotetext{
${ }^{9}$ Fleming, Kirby and Ostdiek (2006) obtain the same result for 20 stocks in the MMI (NYSE). Among the growing evidence that points out to stock volatility as a long-memory process we can find, for instance, Ding, Granger, and Engle (1993), Breidt, Crato and de Lima (1994), and Andersen et al. (2001). Nonetheless, Fujihara and Mougoué (1997) and Wang and Yau (2000) show that the introduction of the current and/or lagged volume and open interest substantially reduced the persistence of volatility for oil futures or Deutsche mark, silver, and gold futures contracts.
} 
days that correspond to the $5 \%$ of the observations for which the RNOP value is closest to zero, and zero the remaining days. The second dummy variable is $R N O P(95 \%)$ and selects those days with a value for RNOP which is closest to +1 . It takes the value 1 the days corresponding to the $5 \%$ of the observations of $R N O P$ with the highest value (the observations higher than the $95^{\text {th }}$ percentile). The third is $R N O P(5 \%)$ and selects the $5 \%$ of the days for which RNOP takes a value lower than its $5^{\text {th }}$ percentile, and it takes the value 1 on those days and zero otherwise.

RNOP(50\%) is directly included in the model. This is designed to capture a possible (average) additional relationship between the trading-related variables included in the model and volatility on those days in which almost every trader who has opened a position has closed it before the market close. $\mathrm{RNOP}(95 \%)$ is included in the model multiplied by OP. The multiplication is equivalent to a truncated variable that takes the value OP on those days with RNOP(95\%) equal to 1, and zero otherwise. It is designed to capture a possible distinct relationship between OP and volatility precisely on those days for which most traders are opening positions. Finally, RNOP(5\%) is included in the model multiplied by CL. This is equivalent to a truncated variable that takes the value of CL whenever RNOP equals 1 and zero otherwise. It will capture a possible distinct relation between CL and volatility on days for which most traders are closing positions.

We used the following estimation procedure. Firstly, the appropriate number of the lags $(L)$ is determined with the next system: we aggregate one lag starting with lowest one $(l=1)$. Next, we check if the coefficient is significant or not at the $99 \%$ level of confidence. If so, we aggregate to the autoregressive model the following lag $(l=2)$ and we check both the significance of the two coefficients and whether the new model improves in terms of adjusted R-squared, Akaike criterion and Schwarz criterion. In that case, we introduce a new lag. If not, we get the final number of lags. All the regressions have been carried out using the Newey and West correction that accounts for heteroskedasticity and serial correlation. Secondly, we estimate the remaining coefficients and we report the adjusted R- 
squared, Akaike criterion and Schwarz criterion for the final model. Table 2 reports the estimation results. $^{10}$

\section{TABLE 2. REGRESSIONS OF VARIANCE ON OPEN AND CLOSED POSITIONS AND $R_{N O P}$ MEASURE}

This table presents the coefficients and their associated probability of the regressions between variance and a constant $\left[\alpha_{0}\right]$, the lags of the volatility $\left[\alpha_{1}, \ldots, \alpha_{9}\right]$, open positions on the day $\mathrm{t}$ and day $\mathrm{t}-1\left[\beta_{0}, \beta_{1}\right]$, closed positions on day $\mathrm{t}$ and day $\mathrm{t}-1\left[\gamma_{0}, \gamma_{1}\right]$ and $R N O P(50 \%)_{t}, O P_{t} \times R N O P(95 \%)_{t}$, and $C L_{t} \times R N O P(5 \%)_{t}\left[\delta_{1}, \delta_{2}, \delta_{3}\right]$, for S\&P 500, DAX and Nikkei index futures daily series for the period from December 2, 1991 to April 30, 2008.

\begin{tabular}{|c|c|c|c|c|c|c|}
\hline & \multicolumn{2}{|c|}{ S\&P 500} & \multicolumn{2}{|c|}{ DAX } & \multicolumn{2}{|c|}{ Nikkei } \\
\hline & Coefficient & Prob. & Coefficient & Prob. & Coefficient & Prob. \\
\hline$a_{0}$ & $-3.9900 E-06$ & 0.9798 & 2.8200E-04 & 0.0886 & $6.9500 \mathrm{E}-04$ & 0.0001 \\
\hline$\alpha_{1}$ & 2.8632E-01 & 0.0000 & 2.6533E-01 & 0.0000 & $2.7842 \mathrm{E}-01$ & 0.0000 \\
\hline$\alpha_{2}$ & $1.9486 \mathrm{E}-01$ & 0.0000 & 1.7022E-01 & 0.0000 & $1.5404 \mathrm{E}-01$ & 0.0000 \\
\hline$\alpha_{3}$ & 1.0015E-01 & 0.0000 & 1.2888E-01 & 0.0000 & 1.4357E-01 & 0.0000 \\
\hline$\alpha_{4}$ & $5.0161 \mathrm{E}-02$ & 0.0064 & 6.4787E-02 & 0.0022 & 1.6935E-02 & 0.4293 \\
\hline$\alpha_{5}$ & $5.4240 \mathrm{E}-02$ & 0.0069 & 7.0105E-02 & 0.0133 & 4.5373E-02 & 0.0417 \\
\hline$\alpha_{6}$ & 4.6058E-02 & 0.0084 & 4.6984E-02 & 0.0151 & 6.1982E-02 & 0.0034 \\
\hline$\alpha_{7}$ & 6.5139E-02 & 0.0012 & 5.1166E-02 & 0.0114 & $8.4051 \mathrm{E}-02$ & 0.0000 \\
\hline$\alpha_{8}$ & $9.2391 \mathrm{E}-02$ & 0.0000 & $6.4570 \mathrm{E}-02$ & 0.0003 & 3.3436E-02 & 0.0968 \\
\hline$\alpha_{9}$ & & & 4.9152E-02 & 0.0172 & 5.4615E-02 & 0.0062 \\
\hline$\beta_{0}$ & $5.3500 \mathrm{E}-08$ & 0.0000 & $3.2000 \mathrm{E}-08$ & 0.0000 & 5.8600E-08 & 0.0000 \\
\hline$\beta_{1}$ & $-4.3600 \mathrm{E}-08$ & 0.0000 & $-2.4200 \mathrm{E}-08$ & 0.0000 & $-4.0400 \mathrm{E}-08$ & 0.0000 \\
\hline$\gamma_{0}$ & $6.5600 \mathrm{E}-09$ & 0.0846 & $1.9100 \mathrm{E}-08$ & 0.0034 & $4.3400 \mathrm{E}-08$ & 0.0055 \\
\hline$\gamma_{1}$ & -7.1400 E-09 & 0.0448 & $-2.1600 \mathrm{E}-08$ & 0.0006 & $-5.4100 \mathrm{E}-08$ & 0.0000 \\
\hline$\delta_{1}$ & $-1.4400 \mathrm{E}-04$ & 0.4635 & $5.0300 E-05$ & 0.8674 & 2.8800E-05 & 0.8949 \\
\hline$\delta_{2}$ & 1.1400E-08 & 0.0504 & 3.9200E-08 & 0.0016 & 1.4900E-08 & 0.0509 \\
\hline$\delta_{3}$ & 6.6200E-09 & 0.0175 & 9.7400E-09 & 0.1038 & 2.6600E-08 & 0.0254 \\
\hline Adjusted R-squared & 0.57 & & 0.60 & & 0.465 & \\
\hline Akaike info criterion & -8.92 & & $-8.4 €$ & & -8.74 & \\
\hline Schwarz criterion & -8.90 & & -8.43 & & -8.70 & \\
\hline
\end{tabular}

\footnotetext{
${ }^{10}$ We checked that our data do not present multicollinearity problems between the open and closed variables. Specifically, we take the residuals of a regression of closed positions on open position, which are orthogonal to the open positions variable, and repeat the regression in equation (16) with the residuals instead of the closed positions series. We obtained similar results.
} 
An autoregressive model of eight lags is used in the S\&P 500 data, while an AR(9) is employed in DAX 30 and Nikkei 225 data.

\subsection{VOLATILITY AND THE NUMBER OF OPEN AND CLOSED POSITIONS}

Table 2 shows that there is a positive relationship between contemporaneous OP and volatility. On the contrary, in the S\&P 500 case, it does not exist relationship between contemporaneous CL and volatility, and therefore only the volume that comes from the opening positions in the futures markets adds volatility to the market. On the other hand, for DAX and Nikkei both contemporaneous OP and CL are positively related to volatility, both increasing volatility to the markets. For all three indexes, there are negative relationships between volatility and lagged OP and CL. The different sign of the contemporaneous and lagged variables coefficient can indicate that the OP and CL change play an important role with the increasing of the volatility for all indexes.

\subsection{OTHER AGGREGATED TRADING-RELATED VARIABLES}

It is possible to infer the empirical relationship between volatility and V and OI, from our results, given the accounting relationships that link them to the OP and CL variables (both contemporaneous and lagged). In other words, our results admit a complementary interpretation in terms of the traditional trading variables.

Developing the contracting variables of the equation (16) using the equations (4) and (5), it can be showed that the expression $\beta_{0} O P_{t}+\beta_{1} O P_{t-1}+\gamma_{0} C L_{t}+\gamma_{1} C L_{t-1}$ is equivalent to $\beta_{0}\left[V O L_{t}+\Delta O I_{t}\right]+\beta_{1}\left[V O L_{t-1}+\Delta O I_{t-1}\right]+\gamma_{0}\left[V O L_{t}-\Delta O I_{t}\right]+\gamma_{1}\left[V O L_{t}-\Delta O I_{t}\right]$, and therefore, equal to $\left[\beta_{0}+\gamma_{0}\right] V O L_{t}+\left[\beta_{1}+\gamma_{1}\right] V O L_{t-1}+\left[\beta_{0}-\gamma_{0}\right] \Delta O I_{t}+\left[\beta_{1}-\gamma_{1}\right] \Delta O I_{t}$. 
Now, we can infer the link between volume and open interest change with volatility testing the significance of the sum and the subtraction of the coefficients that are on their left side, i.e. $H_{0}: \beta_{0}+\gamma_{0}=0$ to test the relationship contemporaneous volume and volatility and so on and so forth.

\section{TABLE 3: HYPOTHESIS TESTING}

This table presents the coefficients of the F-statistics and their associated probability for the Wald tests, for S\&P 500, DAX and Nikkei index futures daily series for the period from December 2, 1991 to April 30, 2008.

Testing trading variables from contracting variables

\begin{tabular}{|c|c|c|c|c|c|c|c|}
\hline \multirow[b]{2}{*}{$\mathbf{H}_{0}$} & \multirow[b]{2}{*}{$\begin{array}{c}\text { Equivalent } \\
\text { Variable }\end{array}$} & \multicolumn{2}{|c|}{ S\&P 500} & \multicolumn{2}{|c|}{ DAX } & \multicolumn{2}{|c|}{ Nikkei } \\
\hline & & Coefficient & p-value & Coefficient & p-value & Coefficient & p-value \\
\hline$\beta(0)+\gamma(0)=0$ & VOL $_{t}$ & 6.01E-08 & 0 & 5.11E-08 & 0 & $1.02 \mathrm{E}-07$ & 0 \\
\hline$\beta(1)+\gamma(1)=0$ & $\mathrm{VOL}_{\mathrm{t}-1}$ & $-5.07 \mathrm{E}-08$ & 0 & $-4.58 \mathrm{E}-08$ & 0 & $-9.46 \mathrm{E}-08$ & 0 \\
\hline$\beta(0)-\gamma(0)=0$ & $\Delta \mathrm{OI}_{\mathrm{t}}$ & $4.70 \mathrm{E}-08$ & 0 & $1.29 \mathrm{E}-08$ & 0.2848 & $1.53 \mathrm{E}-08$ & 0.5858 \\
\hline$\beta(1)-\gamma(1)=0$ & $\Delta \mathrm{OI}_{\mathrm{t}-1}$ & $-3.64 \mathrm{E}-08$ & 0 & $-2.61 E-09$ & 0.8133 & 1.37E-08 & 0.3978 \\
\hline
\end{tabular}

Test outcomes reported in Table 3 show that our results are in line with a positive relationship between volatility and contemporaneous volume, which is widely accepted in the literature. Secondly, our results also indicate a negative link with the volume of the previous day (which confirms previous findings by other authors in several stock indexes). Third, there should be only a (positive) relationship between volatility and the change in open interest for the S\&P 500 case. Fourth and finally, that there also should be a (negative) relation between volatility and lagged change in open interest in this index. ${ }^{11}$

\footnotetext{
${ }^{11}$ These results were controlled by running a regression of volatility on contemporaneous volume, lagged volume, change in open interest and lagged OI change (the estimation results can be obtained from the authors upon request). The coefficients and the p-values were the same as they appear in Table III. Moreover, although we change our four variables for these ones, the Adjusted $\mathrm{R}^{2}$, Akaike info criterion, and Schwarz criterion remained the same value, and it confirms that we are working with the same amount of information -although displayed in a different way in our regression and offering new insight about it.
} 


\subsection{ADDITIONAL EFFECTS FOR SPECIFIC DAYS}

We now explore how the basic relationships may change for some specific days characterized by one of the three most significant values of RNOP (namely, zero, one and minus one). We turn again to the empirical results reported in Table 2.

First, the dummy variable RNOP(50\%), which selects those days with a RNOP value close to zero, is not significantly different from zero. This indicates that those days characterized by a number of opening positions close to the number of closing positions do not have a significantly different volatility on average. ${ }^{12}$ Second, in general, the truncated variables, which are related to those days with an extreme value of RNOP, do have a positive relationship with volatility. In particular, the truncated variable related to RNOP(95\%) shows that there is an additional positive effect of OP on those days mostly dominated by newly opened positions (a marginal effect for the S\&P 500 and Nikkei). The truncated variable related to $\mathrm{RNOP}(5 \%)$ shows that there is an additional positive effect of CL on those days mostly dominated by closing positions, except for the DAX case, which shows no relationship. The result obtained for the truncated variable related to $\mathrm{RNOP}(5 \%)$ is particularly relevant because it shows that CL has a positive relationship with volatility, on those days mostly characterized by the closing of positions, although it may not exist a relationship on average when all the days are considered.

\subsection{ALTERNATIVE INTERPRETATIONS}

Following the intuition of Bessembinder and Seguin (1993), who pointed out that many speculators (informed traders) are “day traders” who do not hold open positions overnight while hedging activity (uninformed trading) is reflected by open interest, Lucia and Pardo (2010) demonstrate that the use of open interest change, instead of the level value or the absolute value of open interest change, is more appropriate in order to reflect the hedging activity. Thus, they defined the so-called $R 3$ ratio $(R N O P)$ of the change in open interest to

\footnotetext{
${ }^{12}$ We also checked for the significance of the truncated variable defined by: $\left[\left(O P_{t}+C L_{t}\right) \times R N O P(50 \%)_{t}\right]$, and it was also equal to zero.
} 
volume in order to measure speculation versus hedging activity. They also pointed out that a value of the ratio closed to zero can be associated to day-traders, whereas the two extreme values (namely, -1 and 1 ) can be related to uninformed traders.

Motivated by these insights, we now provide an alternative interpretation to the relevant values of RNOP. The results that we can extract from Table 2 are mainly two. Firstly, the coefficients of the $R N O P(50 \%)$ are never significant, and therefore, we can conclude that a market session fully dominated by day-traders does not increase the volatility on that day. Secondly, we observe in the three markets that when the hedgers are opening $(R N O P(95 \%))$ and closing $(R N O P(5 \%))$ massively positions in the futures market, they add volatility to the trading day.

\section{CONCLUSIONS}

A number of papers have analyzed the influence of both the volume and the open interest on index future volatility. However, as our results confirm, there is no general conclusions for all the stock indexes. Indeed, whereas the sign of the correlation between volatility and volume of trading (both contemporaneous and lagged) is the same in all the cases, the relationship with (the change in) open interest has not the same property.

This is an empirical puzzle that can be resolved when volatility is related to contracting activity instead of trading activity. Indeed, when open and closed positions are substituted for the traditional variables such as volume and (change in) open interest, the results are essentially the same for all the indexes, which confirms the real contribution of this change in perspective.

In summary, our results show that, for the studied stock indexes, in general both the number of contemporaneous (respectively, lagged) open and closed positions are positively (negatively) correlated with volatility, although in the S\&P 500 case, only contemporaneous number of open positions has influence on volatility, which confirms the importance of studying the contracting activity separately. The coherency of these general 
conclusions is achieved when volatility is analysed under a contracting perspective, which is in sharp contrast with the lack of homogeneity that is observed when volatility is related instead to traditional volume and open interest aggregated variables as it is done in the previous literature.

Our results can be reconciled with the line of reasoning that relates volatility to the activity of groups of traders, such as speculators or informed traders versus hedgers or uninformed traders. According to our findings, day-traders are not associated to an increment of the volatility, whereas uninformed traders, both opening and closing their positions, have to do with a rise in volatility. 


\section{REFERENCES}

Andersen, T. G., Bollerslev, T., Diebold, F.X., and Ebens H. (2001). The distribution of stock return volatility. Journal of Financial Economics, 61, 43-76.

Ap Gwilym, O., Buckle, M., and Evans, P. (2002). The volume-maturity relationship for stock index, interest rate and bond futures contracts. EBMS Working Paper EBMS/2002/3

Ap Gwilym, O., MacMillan, D., Speight A. (1999). The intraday relationship between volume and volatility in LIFFE futures markets. Applied Financial Economics, 9, 593-604.

Bessembinder, H., and Seguin P. (1993). Price Volatility, Trading Volume, and Market Depth: Evidence from Futures Markets. Journal of Financial and Quantitative Analysis, 28, 1, pg. 21.

Breidt. F. J., de Lima, P., and Crato, N. (1994). Modeling long memory stochastic volatility. Working Papers in Economics, No 323, Johns Hopkins University.

Carchano, O., and Pardo, A. (2009). Rolling over stock index futures contracts. Journal of Futures Markets, 29, No. 7, 684-694.

Chen, N.-F., C.J. Cuny, and Haugen R.A. (1995). Stock volatility and the levels of the basis and open interest in futures contracts. Journal of Finance, 50, 281-300.

Conrad, J. S., Hameed, A., and Niden, C. (1994). Volume and autocovariances in shorthorizon individual security returns. Journal of Finance, 49 (4), 1305-1329.

Ding, Z., Granger C., and Engle R. F. (1993). A long memory property of stock market returns and a new model. Journal of Empirical Finance, 1, 83-106.

Duong, H. N., and Kalev P. S. (2008). The Samuelson hypothesis in futures markets: An analysis using intraday data. Journal of Banking \& Finance, 32, 489-500. 
Epps, T. W., Epps, L. M. (1976). The stochastic dependence of security price changes and transaction volumes: implications for the mixture-of-distribution hypothesis. Econometrica, 44, 305-321.

Figlewski, S. (1981). Futures Trading and Volatility in the GNMA Market. Journal of Finance, 36, 445-456.

Fleming J., Kirby C., and Ostdiek B. (2006). Stochastic Volatility, Trading Volume, and the Daily Flow of Information. Journal of Business, 79, No. 3.

Foster, F. J. (1995). Volume-volatility relationships for crude oil futures markets. Journal of Futures Markets, 15, Is. 8, 929-951.

Fung, H. G., and Patterson, G. A. (1999). The dynamic relationship of volatility, volume, and market depth in currency futures markets. Journal of International Financial Markets, Institutions and Money, 17, 33-59.

Fujihara, R. A., and Mougoue M. (1997). Linear dependence, nonlinear dependence and petroleum futures market efficiency. Journal of Futures Markets, 17, Is. 1, 75-99.

Gannon, G.L. (1995). Simultaneous Volatility Effects in Index Futures. Review of Futures Market, 13, No. 4, 25-44.

Garcia, P., Leuthold, M. R., and Zapata, H. (1986). Lead-lag relationships between trading volume and price variability: New evidence. Journal of Futures Markets, 6, Is. 1, 110.

Garman, M. B., and Klass, M. J. (1980). On the estimation of security price volatilities from historical data. Journal of Business, 53, no 1, 67-78.

Kawaller I. G., Koch P. D., and Peterson J. E. (1994). Assessing the Intra-day Relationship between Implied and Historical Volatility. Journal of Futures Markets, 18, No 4, 399-426. 
Li, J.H. (2008). The relationship between return volatility and trading activity in Asia stock index futures. Doctoral Dissertation.

Lucia, J. J., and Pardo, A. (2010). On measuring speculative and hedging activities in futures markets from volume and open interest data. Applied Economics , 42, $1549-1557$.

Martinez, V., and Tse, Y. (2008). Intraday Volatility in the Bond, Foreign Exchange, and Stock Index Futures Markets. Journal of Futures Market, 28, 953-975.

Newey, W., and West, K. (1987). Hypothesis testing with efficient method of moment estimation. International Economic Review, 28, 777-787.

Parkinson, M. (1980). The extreme value method for estimating the variance of the rate of return. Journal of Business, 53, No. 1, 61-65.

Pati, P.C. (2008). The relationship between price volatility, trading volume and market depth: Evidence from an emerging Indian stock index futures market. South Asian Journal of Management, 15, No. 2, pg 25.

Ripple R.D., and Moosa I. A. (2009). The effect of maturity, trading volume, and open interest on crude oil futures price range-based volatility. Global Finance Journal, 20, 209-219.

Rogers, L. C. G., and Satchell S. E. (1991). Estimating variance from high, low and closing prices. Annals of Applied Probability, 1, No. 4, 504-512.

Rogers, L. C. G.; Satchell, S. E.; and Yoon, Y. (1994). Estimating the volatility of stock prices: A comparison of methods that use high and low prices. Applied Financial Economics, 4, Is. 3, 241-47.

Schwert, G. W. (1989). Why does stock market volatility change over time. Journal of Finance, 44, 1115-1153. 
Schwert, G. W., (1990). Stock Market Volatility. Financial Analysis Journal, 46, 3, pg 23.

Smirlock, M., and Starks, L. (1985). A further examination of stock price changes and transactions volume. Journal of Financial Research, 8, 217-225.

Wang, G., and Yau, J. (2000). Trading volume, bid-ask spread, and price volatility in futures markets. Journal of Futures Markets, 20, Is. 10, 943-970.

Wang, C. (2002). The Effect of Net Positions by the Type of Trader on Volatility in Foreign Currency Futures Markets. Journal of Futures Markets, 22, No. 5, 427-450.

Watanabe, T. (2001). Price volatility, trading volume, and market depth: Evidence from the Japanese Stock Index Futures Market. Applied Financial Economics, 11, 651658.

Yang, J., Balyeat R. B., and Leatham D. J. (2005). Futures Trading Activity and Commodity Cash Price Volatility. Journal of Business Finance \& Accounting, 32, No. 1-2, 297-323.

Yang, D., Q. Zhang, (2000). Drift-Independent Volatility Estimation Based on High, Low, Open, and Close Prices. Journal of Business, 73, No. 3. 